\title{
Zur Verteilung von Paraproteinämien nach Geschlecht und Alter der Patienten, Paraprotein-Klassen, -Subklassen und -Leichtketten-Typen
}

\author{
Von A. Oberdorfer, Karin Schnauffer, H.-J. Lange und A. Neiss
}

Institut für Klinische Chemie und Klinische Biochemie (Direktor: Prof. Dr. A. Oberdorfer) und Institut für Medizinische Statistik, Dokumentation und Datenverarbeitung (Vorstand: Prof. Dr. H.-J. Lange) der Technischen Universität München

(Eingegangen am 14. Juli 1972)

Die immunoelektrophoretische Analyse von 837 Paraproteinämien (484 Männer, 340 Frauen, 13 Fälle ohne Geschlechtsangabe; Durchschnittsalter 65 Jahre) ergab folgende Klassenverteilung: 63,9\% IgG-, 17,2\% IgA-, 0,8\% IgD-, 12,7\% IgM-, 3,7\% Leichtketten- und 1,7\% Mehrfach-Paraproteinämien. Bei der Bestimmung des Leichtketten-Typs wurden folgende Kappa:Lambda-Verhältnisse festgestellt: 1,3:1 im Gesamtmaterial, 1,4:1 bei IgG-, 1,2:1 bei IgA-, 2,4:1 bei IgM-, 0,8:1 bei Leichtketten-Paraproteinämien. Die Subklassenverteilung von 138 IgG-Paraproteinämien ist folgende: $73 \%$ IgG1, 12\% IgG2, 8\% IgG3, 7\% IgG4. In den Subklassen IgG1, IgG2 und IgG4 überwiegen die Fälle mit Kappa-Leichtketten; in der Subklasse IgG3 wurde ein Kappa:Lambda-Verhältnis von 0,4:1 gefunden. Von 44 auf Subklassenverteilung untersuchten IgA-Paraproteinämien entfallen 42 auf die Subklasse IgA1 (Kappa:LambdaVerhältnis $=1,8: 1$ ) und 2 Fälle auf die Subklasse IgA2.

\section{The distribution of paraproteinaemias according to the sex and age of patients; Classes, subclasses and light chain types of paraproteins.}

The immunoelectrophoretic analysis of 837 paraproteinaemias (samples from 484 men, 340 women, 13 of unstated sex; average age 65 years) showed the following distribution: $63.9 \%$ IgG-, $17.2 \%$ IgA-, $0.8 \%$ IgD-, $12.7 \%$ IgM-, 3.7\% light chain-, and $1.7 \%$ multiple paraproteinaemias. The following ratios were determined for kappa:lambda in the light chain type: 1.3:1 in the total material, 1.4:1 for IgG-, 1.2:1 for IgA-, 2.4:1 for IgM-, 0.8:1 for the light chain- paraproteinaemias. The distribution of 138 IgG-paraproteinaemias in subclasses was: $73 \%$ IgG1, 12\% IgG2, 8\% IgG3, 7\% IgG4. In the IgG1, IgG2 and IgG4, the cases of kappa-light chains predominated; the subclass IgG3 showed a kappa:lambda ratio 0.4:1. Out of $44 \operatorname{IgA-paraproteinaemias,~} 42$ were in subclass IgA1 (kappa:lambda ratio $1.8: 1$ ) and 2 were in subclass IgA2.

Bei Paraproteinämien sind im Serum der betreffenden Patienten Konzentrationsvermehrungen strukturell und immunologisch homogener Immunoglobuline nachweisbar. In einem Teil der Fälle liegt zusätzlich oder ausschließlich eine Vermehrung einzelner Immunoglobulinbestandteile vor. Die Einteilung der Paraproteinämien kann sowohl nach klinischen Gesichtspunkten als auch auf Grund immunochemischer Kriterien der vermehrt gebildeten Proteine erfolgen.

In dieser Arbeit wird über die Verteilung von Paraproteinämien nach Geschlecht und Alter der Patienten, Paraprotein-Klassen, -Subklassen und -LeichtkettenTypen sowie über die wechselseitigen Beziehungen dieser Größen untereinander berichtet.

\section{Material}

Bei den in dieser Arbeit ausgewerteten Fällen handelt es sich sowohl um Paraproteinämien bei Plasmocytom oder Makroglobulinämie WALDENSTROEM als auch um sog. Begleitparaproteinämien sowie um sog. benigne Paraproteinämien, bei denen kein weiterer Hinweis auf eine Erkrankung im klinischen Sinne vorliegt. Die Diagnosestellung exfolgte ausschließlich aufgrund des immunoelektrophoretischen Befundes.

Das Material beinhaltet insgesamt 837 Fälle aus Einsendungen der Jahre 1963-1972. Es handelt sich dabei um 484 Männer und 340 Frauen; bei 13 Fällen wurde uns das Geschlecht nicht mitgeteilt. Bei 459 Männern und bei 322 Frauen war das Alter.bekannt. 467 Fälle (278 Männer und 176 Frauen, 13 Fälle unbekannten Geschlechts) waren Patienten des Klinikums rechts der Isar und anderer Krankenhäuser der Stadt München; 370 Fälle
(206 Männer und 164 Frauen) stammen von Einsendungen auswärtiger Krankenhäuser und niedergelassener Ärzte.

Zur Frage der Homogenität des Materials wurde untersucht, ob die Geschlechts-, Alters- und Klassenverteilungen innerhalb des Beobachtungszeitraumes (1963-1972) annähernd gleich geblieben sind. Dic Prüfung ergab keine wesentlichen Unterschiede. von Jahr zu Jahr. Aus diesem Grunde ist eine zusammengefaßte Auswertung des Materials gerechtfertigt.

824 Fälle unseres Materials konnten nach dem Geschlecht der Patienten, 783 nach dem Alter der Patienten, alle 837 nach Paraproteinämieklassen, 138 nach IgG-Subklassen, 44 nach IgASubklassen, 678 rach dem Leichtketten-Typ und 643 sowohl nach dem Geschlecht und dem Alter der Patienten als auch nach Paraproteinämieklassen und dem Leichtketten-Typ differenziert werden.

\section{Methodik}

In jedem Serum wurde die Gesamtproteinkonzentration bestimmt (Biuret-Reaktion, Methode nach WeICHSELBAUM (1)) sowie das elektrophoretische und immunoelektrophoretische Serumeiweißbild analysiert. Die immunoelektrophoretische Analyse wurde nach Grabar und Wrlliams $(2,3)$ in der Modifikation von SCHEIDEGGER (4) auf Objektträgern durchgefühtt und nach den von Grabar et al. (5), Burtin et al. (6), Heremans und HeremaNs (7) sowie von HrRemans (8) angegebenen Kriterien ausgewertet.

Die Differenzierung nach Paraprotein-Klassen und -Leichtketten-Typen erfolgte immunoelcktrophoretisch. Die Bestimmung der IgG- und IgA-Subklassen wurde immunoelektrophoretisch, in einigen Fällen zusätzlich auch mit dem Doppeldiffusionstest nach OuchtzRLONY (9) durchgeführt. Methodische Einzelheiten der Immunoglobulin-Subklassenbestimmung siehe SKAVRIL et al. (10). 


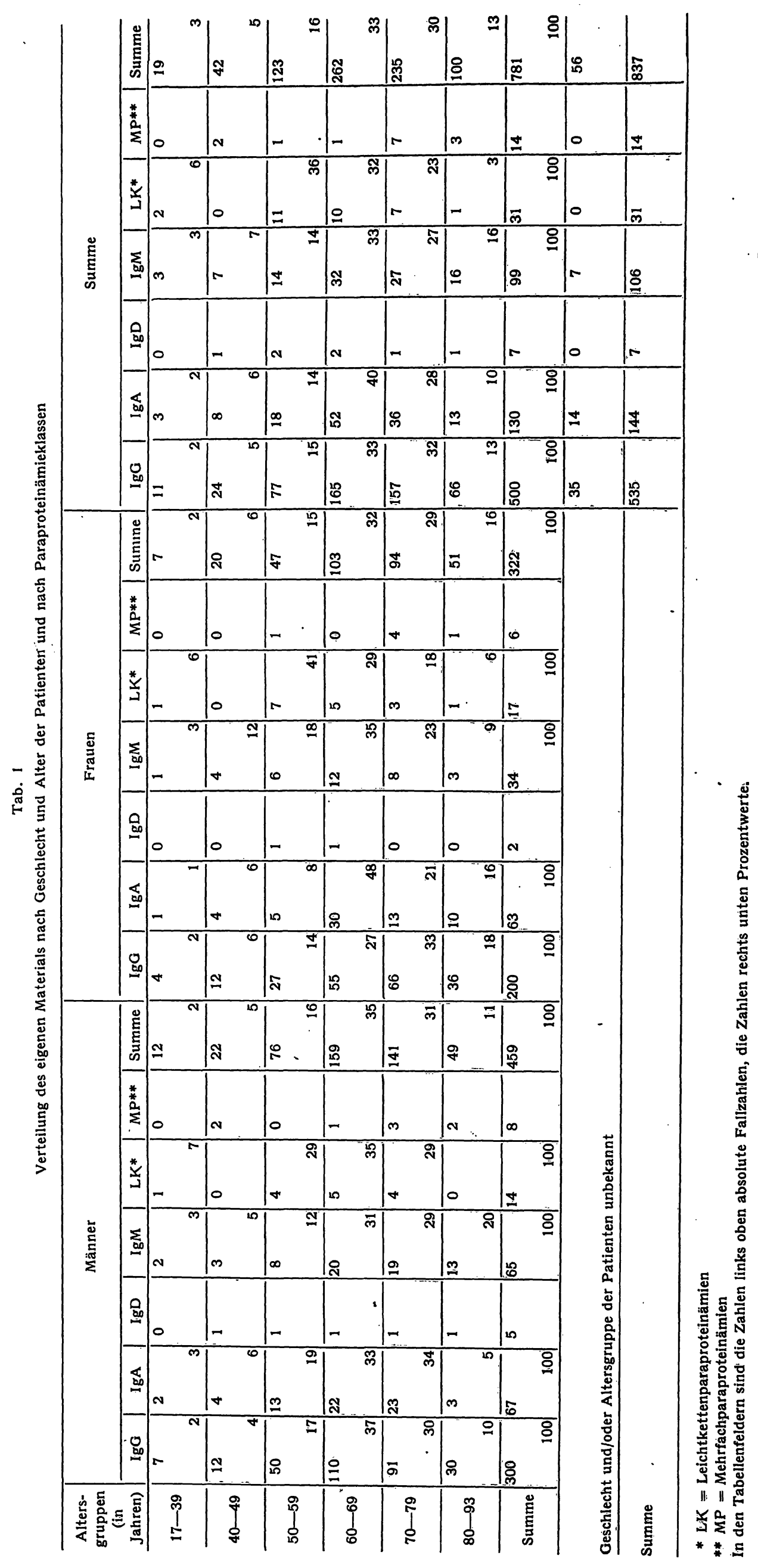

Z. Klin. Chem. Klin. Biochem. / 11. Jahrg. 1973 / Heft 2 
Die mit statistischen Verfahren behandelten Probleme lassen sich wie folgt cintcilen:

1. Testen von Hypothesen:

1. 1 Zusammenhang zwischen zwei in Klassen cingeteilten Merkmalen. Beispicl: Besteht ein Zusammenhang zwischen Geschlecht und Leichtketten-Typ?

1. 2 Vorliegen ciner bestimmten Häufigkeit eines Merkmales' in der Grundgesamtheit. Beispiel: Úberwiegt bei Paraproteinämien das männliche Geschlecht?

2. Schätzen eincr Häufigkeit in der Grundgesamtheit:

Beispicl: Wie groß ist die Häufigkeit des Auftretens von KappaLeichtketten bei IgG-Paraproteinämien in der Grundgesamtheit? 1.1 wird mit Hilfe des $\chi^{2}$-Testes für zweidimensionale Kontingenztafeln behandelt. Die Beantwortung von 1.2 erfolgt unter Zuhilfenahme von Tabellen mit Konfidenzintervallen für den Parameter der Binomialverteilung (Dokumenta Geigy (11)). Liegen für den betrachteten Stichprobenumfang n keine tabellierten Werte vor, so wird in den Tabellen interpoliert oder, falls $n$ genügend groß ist, dic Binomialverteilung durch die Normalverteilung approximiert (HEINHOLD und GAEDE (12)).

Dieses Vorgehen (Berechnung von Konfidenzintervallen) wird auch zur Untersuchung von 2 gewählt. Man erhält dann als Angabe für die gesuchte Häufigkeit nicht einen Wert, sondern ein Intervall. Dieses Intervall hat die Eigenschaft, daß es den ,wahren Häufigkeitswert" (= Häufigkeit in der Grundgesamtheit) mit einer vorgegebenen Sicherheit (z. B. 99\%) überdeckt. Wir betrachten ein Ergebnis als ,signifikant" oder ,statistisch gesichert", wenn die Irrtumswahrscheinlichkeit höchstens $1 \%$ beträgt, als „statistisch auffällig“, wenn sie zwischen $1 \%$ und $5 \%$ liegt.

\section{Ergebnisse}

\section{Verteilung nach dem Geschlecbt der Patienten}

Das eigene Paraproteinämie-Material setzt sich aus 484 Männern und 340 Frauen zusammen. Es wurden demnach mehr Männer als Frauen beobachtet. Der Unterschied gegenüber einer 1:1-Verteilung ist statistisch gesichert.

\section{Verteilung nacb dem Alter der Patienten}

Die Altersverteilung der Paraproteinämiefälle unseres Materials geht aus Abbildung 1 und Tabelle 1 hervor. Die Darstellung bezieht sich auf das Lebensalter der Patienten zum Zeitpunkt der durch uns erfolgten

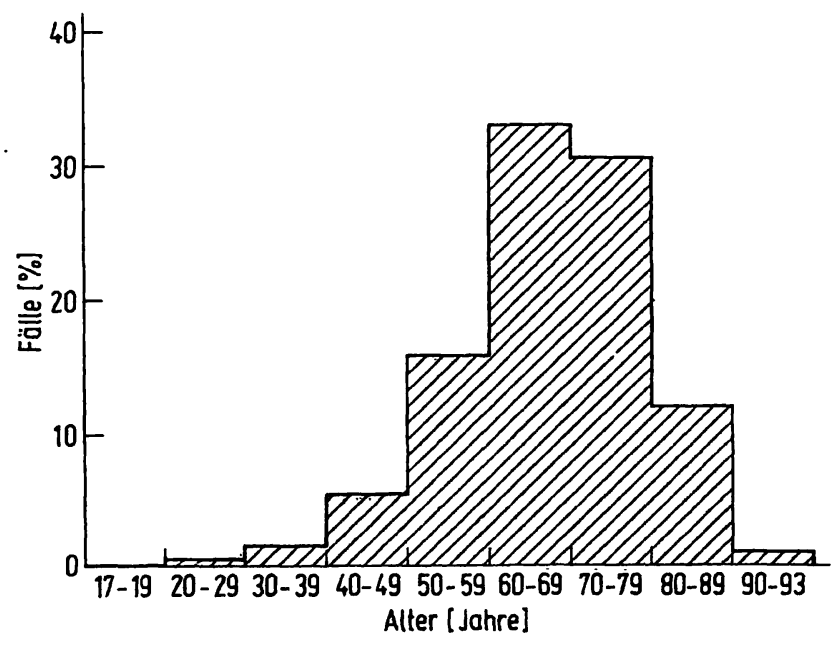

Abb. 1

Prozentuale Verteilung von 783 Paraproteinämien des eigenen Materials nach dem Alter der Patienten
Diagnosestellung. Der Gipfel der Altersverteilung liegt innerhalb der Altersgruppe 60-69 Jahre. Der jüngste Patient unseres Materials war bei der Erstuntersuchung 17 Jahre alt, der älteste 93 Jahre.

Das durchschnittliche Alter bei Männern und Frauen ist jeweils 65 Jahre. Zwischen der Altersverteilung bei Männern und der bei Frauen läßt sich kein signifikanter Unterschied nachweisen.

Innerhalb der Paraproteinämieklassen liegt das Durchschnittsalter von 783 Patienten mit bekanntem Alter wie folgt:

IgG-Paraproteinämien

IgA-Paraproteinämien

IgD-Paraproteinämien

IgM-Paraproteinämien

Leichtketten-Paraproteinämien

Mehrfach-Paraproteinämien

66 Jahre $(\mathrm{n}=502)$

64 Jahre $(\mathrm{n}=130)$

63 Jahre $(\mathrm{n}=7)$

65 Jahre $(\mathrm{n}=99)$

59 Jahre $(\mathrm{n}=31)$

70 Jahre $(\mathrm{n}=14)$

Die Altersverteilungen der Patienten dieser 6 Paraproteinämieklassen unterscheiden sich nicht signifikant.

\section{Verteilung nach Paraproteinämieklassen}

Die Verteilung des eigenen Materials auf IgG-, IgA-, IgD-, IgM-, Leichtketten- und Mehrfach-Paraproteinämien ist aus Tabelle 1 und 2 ersichtlich.

Die Prüfung der 1:1-Hypothese hinsichtlich der innerhalb der einzelnen Paraproteinämieklassen des eigenen Materials vorliegenden Geschlechtsverteilung führte zu folgenden Resultaten:

Signifikant mehr Männer als Frauen wurden gefunden bei IgG-Paraproteinämien (316 Männer, 213 Frauen) und bei IgM-Paraproteinämien (69 Männer, 37 Frauen). Keine statistisch gesicherten Unterschiede der Verteilung auf Männer und Frauen ergaben sich bei IgA-Paraproteinämien (72 Männer, 65 Frauen), IgD-Paraproteinämien (5 Männer, 2 Frauen), Leichtketten-Paraproteinämien (14 Männer, 17 Frauen) und MehrfachParaproteinämien (8 Männer, 6 Frauen).

\section{Verteilung nach Leicbtketten-Typen}

Bei 678 Fällen des eigenen Paraproteinämie-Materials wurde der Leichtketten-Typ bestimmt. In 381 Fällen $(57,4 \%)$ wurde der Kappa-Typ, in 283 Fällen (42,6\%) der Lambda-Typ festgestellt; es ergibt sich damit für das Gesamtmaterial ein Kappa: Lambda-Verbältnis von 1,3:1. Das Überwiegen des Kappa-Typs ist signifikant.

Tab. 2

Verteilung des eigenen Materials nach Paraproteinämieklassen

\begin{tabular}{crr}
\hline $\begin{array}{c}\text { Paraproteinämie- } \\
\text { klasse }\end{array}$ & $\mathrm{n}$ & $\%$ \\
\hline IgG & 535 & 63,9 \\
IgA & 144 & 17,2 \\
IgD & 7 & 0,8 \\
IgM & 106 & 12,7 \\
LK* & 31 & 3,7 \\
MP** & 14 & 1,7 \\
Summe & 837 & 100,0 \\
\hline
\end{tabular}

* LK = Leich tkettenparaproteinämien

** MP = Mehrfachparaproteinämien 
Tab. 3

Verteilung des eigenen Materials nach Paraproteinämieklassen und Leichtkettentypen (mit Ausnahme der in Obersicht 2 aufgeführten 14 Mehrfachparaproteinämien)

\begin{tabular}{|c|c|c|c|}
\hline \multirow{2}{*}{$\begin{array}{l}\text { Paraproteinämie- } \\
\text { klasse }\end{array}$} & \multicolumn{3}{|c|}{ Leichtkettentyp } \\
\hline & Kappa & Lambda & Summe \\
\hline & 270 & 194 & 464 \\
\hline dgu & 57,9 & 42,1 & 100,0 \\
\hline & 65 & 54 & 119 \\
\hline $\mathrm{IgA}$ & 54,6 & . 45,4 & 100,0 \\
\hline IgD & 1 & 5 & 6 \\
\hline $\lg M$ & 70,5 & 13 & 100,0 \\
\hline LK* & 14 & 17 & 100,0 \\
\hline Summe & 381 & 42,6 & 100,0 \\
\hline
\end{tabular}

* LK = Leichtkettenparaproteinämien

In den Tabellenfeldern sind die Zahlen links oben absolute Fallzahlen, die Zahlen rechts unten Prozentwerte.

Zwischen der Leichtkettenverteilung bei Paraproteinämien von Männern und Frauen konnte kein signifikanter Unterschied festgestellt werden.

Die Leichtkettenverteilungen innerhalb der einzelnen Paraproteinämie-Klassen sind aus Tabelle 3, die entsprechenden Kappa:Lambda-Verhältnisse aus Tabelle 12 ersichtlich. Wie aus Tabelle $4 \mathrm{zu}$ entnehmen ist, überwiegen sowohl bei Männern als auch bei Frauen innerhalb der IgG-, IgA- und IgM-Paraproteinämien die Fälle mit Kappa-Ketten.

\section{Verteilung nach Subklassen}

Von 138 IgG-Paraproteinämien 75 Männer, 61 Frauen, 2 Fälle unbekannten 'Geschlechts) und von $44 \operatorname{IgA-}$
Paraproteinämien (20 Männer, 24 Frauen) unseres Materials wurden die Verteilungen nach Subklassen und der Leichtketten-Typ der Subklassen bestimmt. Die Ergebnisse sind in den Tabellen 5 und 6 dargestellt. Die Unterschiede im Kappa: Lambda-Verhältnis der Subllassen IgG1 bis IgG4 sind statistisch auffällig. Man erkennt, daß in der Subklasse IgG3 ein Uberwiegen des Lambda-Typs vorliegt, während in den anderen Subklassen der Kappa-Typ vorherrscht. In der Subklasse IgG4 ist das Leichtkettenverhältnis besonders • stark zu Gunsten des Kappa-Typs verschoben.

\section{Diskussion}

Für die folgende Diskussion wurden aus der Literatur statistische Angaben über die Verteilungen von Paraproteinämien hinsichtlich Geschlecht und Alter der Patienten, Paraptoteinämie-Klassen (einschließlich Mehrfach-Paraproteinämien) und Leichtketten-Typ in Tabellen und Ubersichten zusammengestellt. $\mathrm{Zu}$ derartigen Zusammenstellungen ist grundsätzlich folgendes $\mathrm{zu}$ bemerken: Es fehlen in der Literatur vielfach nähere Angaben über die Herkunft des Patientengutes und die Zusammensetzung der Patientenkollektive im Einzugs: gebiet. Außerdem können auf die Zusammensetzung des Materials noch weitere Faktoren, wie z. B. das besondere wissenschaftliche Interesse des Untersuchers', Einfluß nehmen. Ferner ist zu beachten, daß die für die diagnostische Differenzierung von Paraproteinämien wichtigen Verfahren erst im Laufe der beiden letzten Jahrzehnte schrittweise und an verschiedenen Stellen zu unterschiedlichen Zeitpunkten in das klinișch-chemische Laboratorium eingeführt wurden. Deshalb hat der Zeitpunkt der Untersuchung ebenfalls einen Einfluß auf die von den Autoren veröffentlichten Resultate, wodurch Vergleiche von Ergebnissen verschiedener Zeitperioden erschwert sind. Eine besondere Problematik beim Vergleich immunoelektrophoretischer Untersuchungsergebnisse ist bekanntlich durch die unter-

Tab. 5

Verteilung von IgG-Paraproteinämien auf Subklassen (IgG 1, IgG 2, IgG 3, IgG 4) und Leichtkettentyp

\begin{tabular}{|c|c|c|c|c|c|c|c|c|c|c|c|c|c|c|c|}
\hline & \multicolumn{3}{|c|}{ IgG 1} & \multicolumn{3}{|c|}{$\operatorname{IgG} 2$} & \multicolumn{3}{|c|}{$\operatorname{IgG} 3$} & \multicolumn{3}{|c|}{ IgG 4} & \multicolumn{3}{|c|}{ Insgesamt } \\
\hline & $\%$ & $\lambda$ & Summe & $x$ & $\lambda$ & Summe & $x$ & $\lambda$ & Summe & $x$ & $\lambda$ & Summe & $x$ & $1 \lambda$ & Summe \\
\hline Zahl der Fälle & $\begin{array}{|ll|}64 & \\
& 63 \\
& 63\end{array}$ & 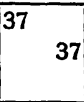 & $\begin{array}{|rr|}101 & \\
& 100 \\
& 73 \\
\end{array}$ & 9 & 7 & 16 & 3 & 8 & 11 & 9 & 1 & 10 & \begin{tabular}{|ll}
85 & \\
& 62
\end{tabular} & 53 & 13 \\
\hline$x: \lambda$-Verhältnis & & $1,7: 1$ & & & 1,3 : & & & 0,4 & & & 9: & & & $1,6: 1$ & \\
\hline
\end{tabular}

In den Tabellenfeldern sind die Zahlen links oben absolute Fallzahlen, die Zahlen in der Mitte Prozentwerte, bezogen auf die Fallzahl in der jeweiligen Subklasse; die Zahlen rechts unten sind Prozentwerte, bezogen auf die gesamte Fallzahl.

Tab. 6

Verteilung von IgA-Paraproteinämien auf Subklassen (IgA 1 und IgA 2) und Leichtkettentyp

\begin{tabular}{|c|c|c|c|c|c|c|c|c|c|}
\hline & \multicolumn{3}{|c|}{ IgA 1} & \multicolumn{3}{|c|}{ IgA 2} & \multicolumn{3}{|c|}{ Insgesämt } \\
\hline & $x$ & $\lambda \mid$ & Summe & $x$ & $\lambda$ & Summe & $* 1$ & $\lambda \mid$ & Summe \\
\hline Zahl der Fälle & $\begin{array}{|ll|}27 & \\
& 64 \\
\end{array}$ & $\begin{array}{|ll|}15 & \\
& 36 \\
& \end{array}$ & $\begin{array}{|rr|}42 & \\
& 100 \\
& 95\end{array}$ & 1 & 1 & 2 & $\begin{array}{|ll|}28 & \\
& 64 \\
\end{array}$ & $\begin{array}{ll}16 & \\
& 36 \\
& \end{array}$ & $\begin{array}{rr}44 & \\
& 100 \\
& 100\end{array}$ \\
\hline$x: \lambda$-Verhältnis & & $1,8: 1$ & $=$ & & & & & $1,8: 1$ & \\
\hline
\end{tabular}

In den Tabellenfeldern sind die Zahlen links oben absolute Fallzahlen, die Zahlen in der Mitte Prozentwerte, bezogen auf die Fallzahl in der jeweiligen Subklasse; die Zahlen rechts unten sind Prozentwerte, bezogen auf die gesamte Fallzahl. 


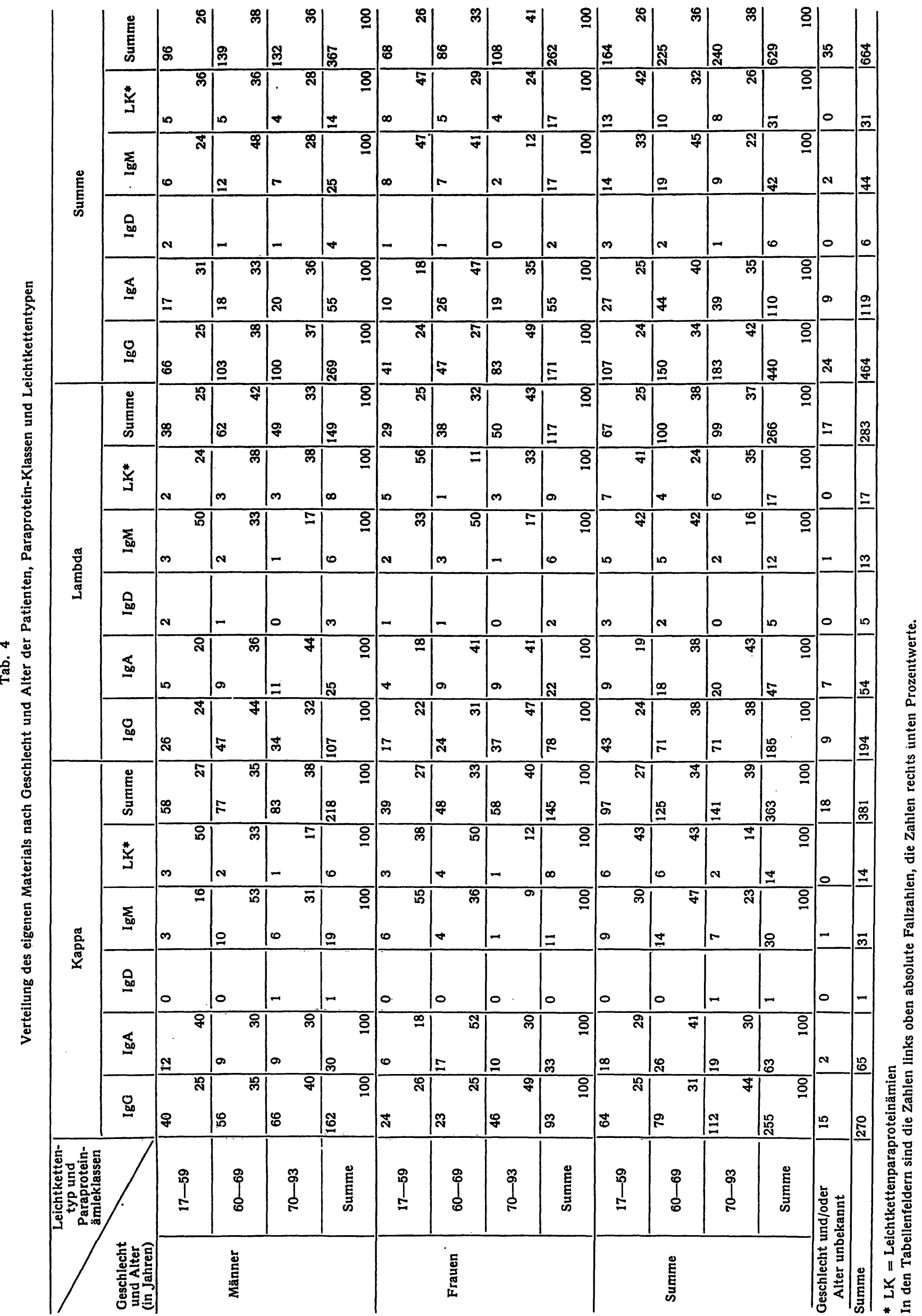


schiedliche und oft nicht genügend definierte Zusammensetzung und Qualität der Antiseren bedingt. Schlußfolgerungen aus zusammengefaßten Materialien verschiedener Autoren erscheinen uns aus den angeführten Gründen bedenklich. Die folgende Diskussion bezieht sich daher vorwiegend auf die eigenen Ergebnisse.

Das im eigenen Paraproteinämie-Gesamtmaterial festgestellte Überwiegen der Männer legt die Frage nahe, ob diese Geschlechtsverteilung für Paraproteinämien charakteristisch oder durch die Zusammensetzung des Patientenmaterials der Einsender beeinflußt ist. Wie oben erwähnt (siehe bei „Material"), handelt es sich bei den beobachteten eigenen Fällen zum Teil um Patienten von Krankenhäusern der Stadt München, zum anderen Teil um Einsendungen auswärtiger Krankenhäuser. Eine Auskunft des Betriebs- und Krankenhausreferates der Landeshauptstadt München ergab, daß während der gesamten Beobachtungszeit jährlich mehr Frauen als Männer in die Krankenhäuser der Stadt München aufgenommen wurden. Nach einer Mitteilung des Amtes für Statistik und Datenanalyse der Landeshauptstadt

Tab. 7

Verteilung von Paraproteinämien nach dem Geschlecht der Patienten

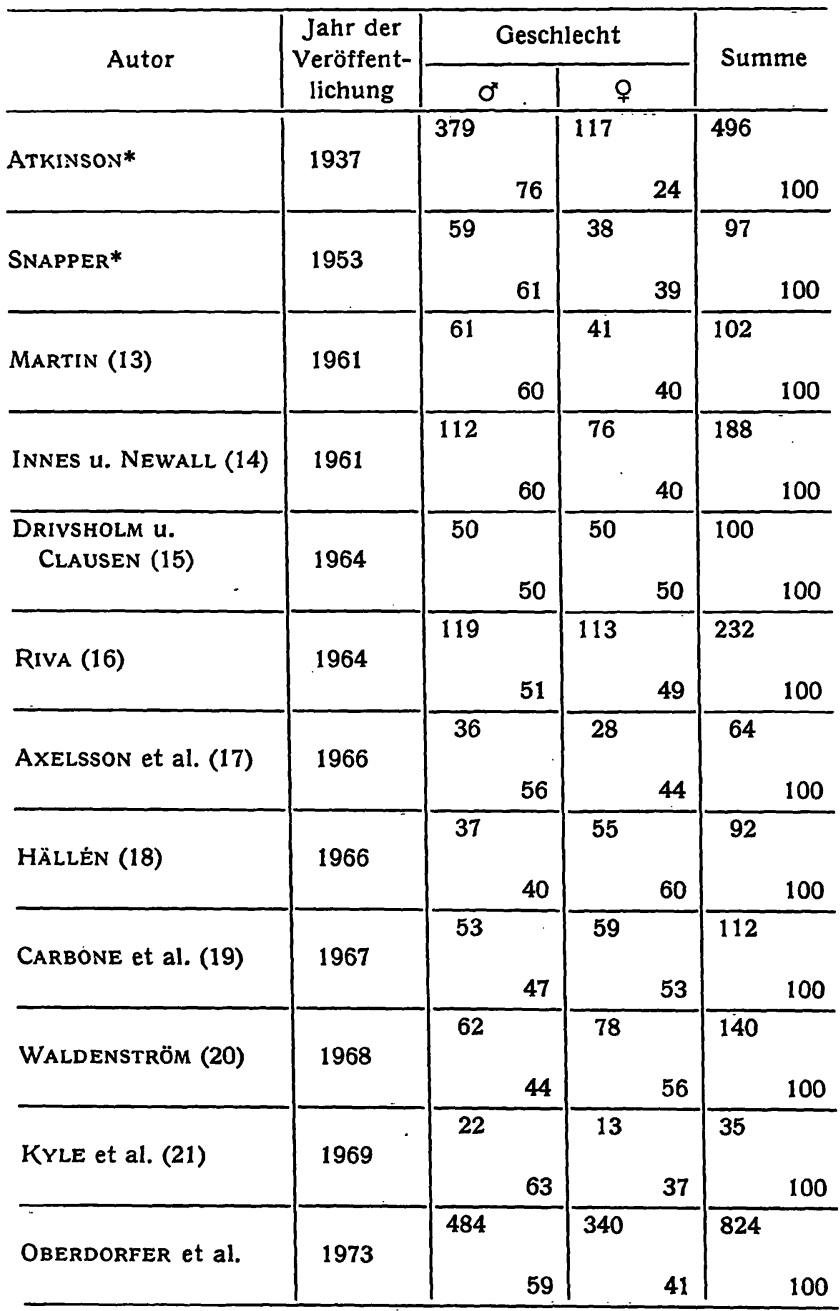

* Zitiert nach Waldenström (1968)

In den Tabellenfeldern sind die Zahlen links oben absolute Fallzahlen, die Zahlen rechts unten Prozentwerte.
München ist die mittlere Verweildauer der Krankenhausaufenthalte in Münchener Krankenhäusern bei weiblichen Patienten länger als bei männlichen. Für den aus dem Einsendebereich der Stadt München stammenden Anteil unserer Paraproteinämie-Fälle kann demnach mit Sicherheit ausgeschlossen werden, da $B$ das Überwiegen des männlichen Geschlechtes durch die Zusammensetzung des Patientengutes der einsendenden Stellen bedingt ist. Die von anderen Autoren mitgeteilte Verteilung von Paraproteinämien nach dem Geschlecht der Patienten ist aus Tabelle 7 ersichtlich. Wie aus der Tabelle zu entnehmen ist, überwiegt bei den meisten Autoren die Zahl der männlichen Patienten.

IsOBE und OsSERMANN (22), die ihr während der Jahre 1952 bis 1971 gesammeltes Paraproteinämiematerial von insgesamt 806 Fällen (sog. Plasmazell-Dyskrasien) nach klinischen Gesichtspunkteñ einteilen, kommen zu der Feststellung, daß Paraproteinämien ohne klinische Symptome und Paraproteinämien mit Carcinomen bei Männern zweimal so häufig vorkommen wie bei Frauen. Paraproteinämien mit Myelomen, Makroglobulinämien oder Amyloidosen sind im Material dieser Autoren auf Männer und Frauen gleich verteilt.

Aus Tabelle 8 geht hervor, welche Altersgruppen im Paraproteinämiematerial anderer Autoren jeweils am häufigsten besetzt sind. Die Mehrzahl der Altersgipfel liegt $z$ wișchen 60 und 69 Jahren.

Die Verteilung des eigenen Materials auf Paraproteinämie-Klassen ist in den Tabellen 9 und 10 den Verteilungen des Paraproteinämiematerials anderer Autoren gegenübergestellt. Auf die weitgehende Übereinstimmung der Verteilung des eigenen Materials mit der Verteilung des aus demselben Einzugsgebiet stammenden Materials von FATEH et al. (46) sei hingewiesen. Vergleiche der Ergebnisse der übrigen Autoren untereinander und mit dem eigenen Material erscheinen uns aus den oben angeführten Gründen (Einzugsgebiet, wissenschaftliches Interesse des Autors, Analysenmethoden usw.) problematisch.

FATEH et al. (46) berichten von einem leichten, jedoch statistisch nicht gesicherten Überwiegen des männlichen Geschlechts in allen Paraproteinämieklassen. Das im eigenen Gesamtmaterial festgestellte Überwiegen des männlichen Geschlechtes ist vorwiegend auf die $\mathrm{Ge}$ schlechtsrelation bei IgG- und IgM-Paraproteinämien zurückzuführen.

Während bei den IgG-, IgA-, IgD- und IgM-Paraproteinämien des eigenen Materials die Durchschnittsalterswerte um 65 Jahre liegen, fällt auf, daß das durchschnittliche Alter bei den Leichtketten-Paraproteinämien 59 Jahre, dasjenige bei den Mehrfach-Paraproteinämien dagegen 70 Jahre beträgt. Ein Uberwiegen des jüngeren Alters bei Leichtketten-Paraproteinämien wurde auch von HobBs (27) sowie von Dúgue et al. (48) beobachtet. Wie aus Übersicht 1 entnommen werden kann, entspricht auch bei Mehrfach-Paraproteinämien der Altersbereich der Fälle unseres Materials der von anderen Autoren mitgeteilten Altersspanne. 
Tab. 8 Position* des Gipfels der Altersverteilung von Paraproteinämien**

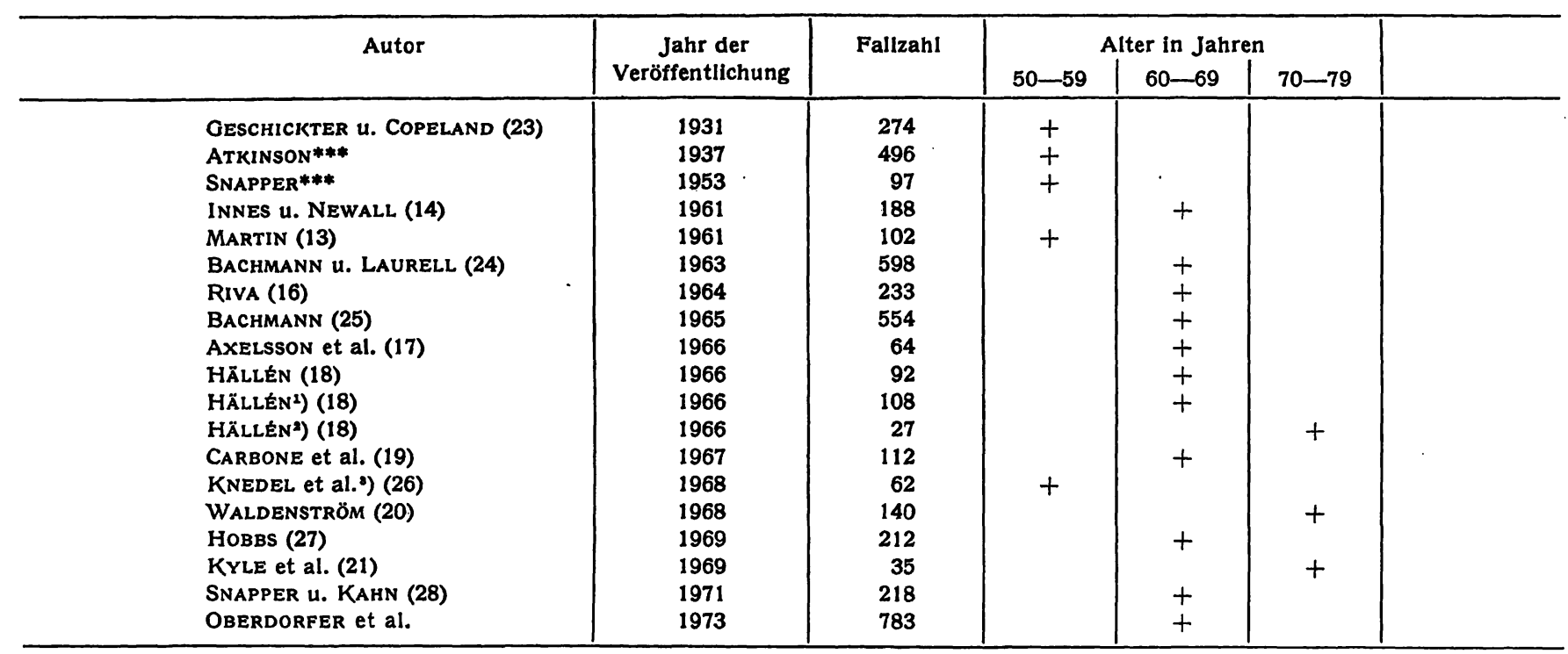

* In der Tabelle durch + gekennzeichnet

** Veröffentlichungen ohne Angaben über Fallzahlen sowie Kasuistiken von weniger als 30 Fällen wurden in der Tabelle nicht berücksichtigt *** Zitiert nach WALDENSTRÖM (20)

2) „Benigne Gammopathien" mit IgG- und IgA-Paraproteinämien.

2) „Benigne Gammopathien" mit IgM-Paraproteinämien.

3) „Benigne Gammopathien“ mit IgG-Paraproteinämien.

Tab. 9 Verteilung von Paraproteinämien nach Paraproteinämieklassen (IgG, IgA, IgD, IgM, LK*, MP**)

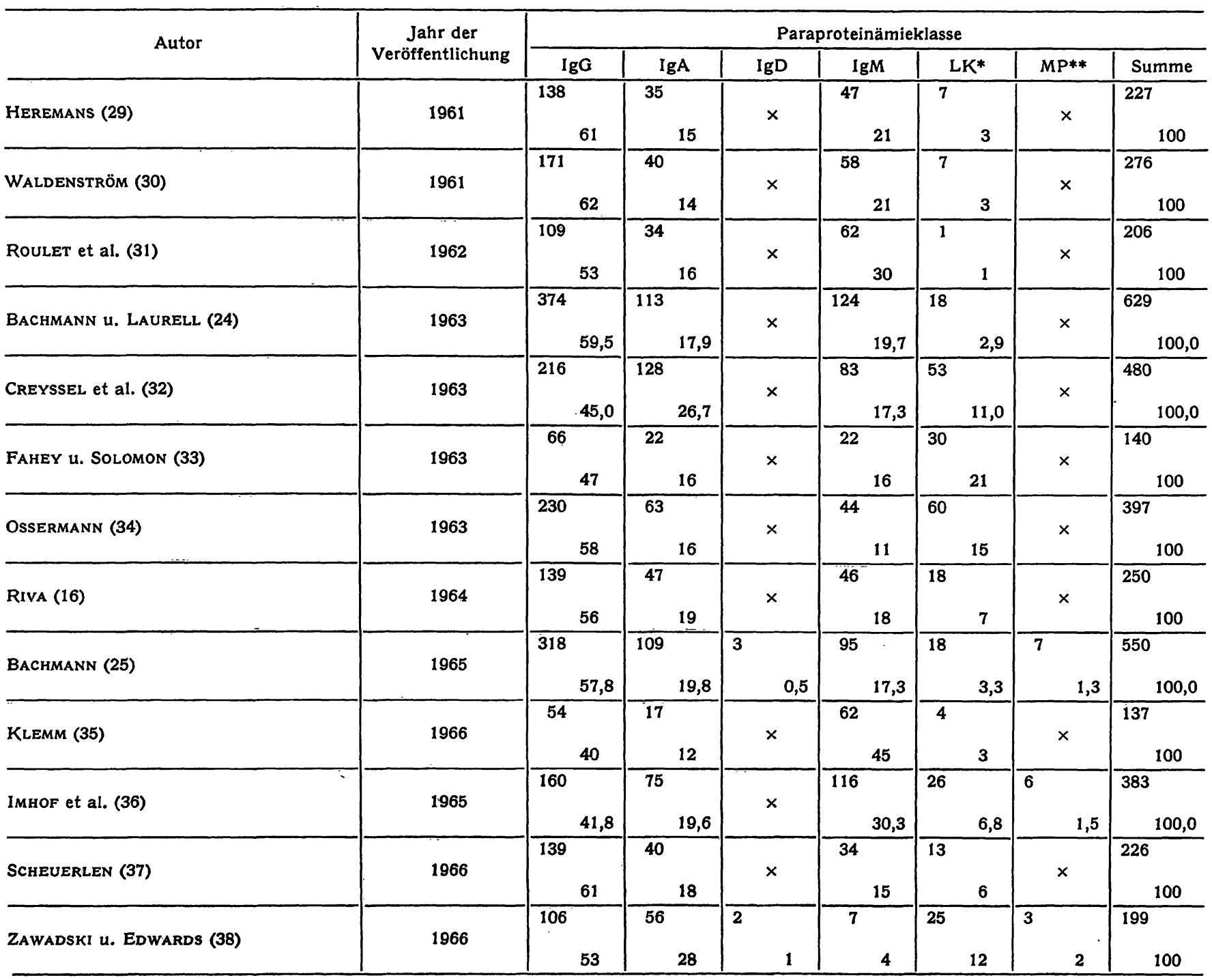


Tabelle 9 (Fortsetzung)

\begin{tabular}{|c|c|c|c|c|c|c|c|c|}
\hline \multirow{2}{*}{ Autor } & \multirow{2}{*}{$\begin{array}{c}\text { Jahr der } \\
\text { Veröffentlichung }\end{array}$} & \multicolumn{7}{|c|}{ Paraproteinämieklasse } \\
\hline & & IgO & IgA & IgD & $\operatorname{IgM}$ & LK* & $M P * *$ & Summe \\
\hline AXELsson et al. (17) & 1966 & $\begin{array}{r}39 \\
\quad 61 \\
\end{array}$ & $\begin{array}{l}17 \\
\quad 26 \\
\end{array}$ & $x$ & $\begin{array}{rr}5 & \\
& 8 \\
\end{array}$ & $x$ & $\begin{array}{ll}3 & \\
& 5 \\
\end{array}$ & $\begin{array}{r}64 \\
100 \\
\end{array}$ \\
\hline MEISER U. HUHNSTOCK (39) & 1967 & $\begin{array}{r}54 \\
\quad 60 \\
\end{array}$ & $\begin{array}{rr}13 & \\
& 14 \\
\end{array}$ & $x$ & $\begin{array}{ll}15 & \\
& 17 \\
\end{array}$ & 8 & 1 & $\begin{array}{l}0 \\
\quad 100 \\
\end{array}$ \\
\hline Paraskevas (40) & 1967 & $\begin{array}{rr}24 & \\
& 45 \\
\end{array}$ & $\begin{array}{r}11 \\
\quad 20 \\
\end{array}$ & $x$ & $\begin{array}{r}5 \\
\quad 9 \\
\end{array}$ & \begin{tabular}{|ll}
13 & \\
& \\
& 24 \\
\end{tabular} & $\begin{array}{lll}1 & \\
1 & 2 \\
\end{array}$ & $\begin{array}{r}54 \\
\quad 100 \\
\end{array}$ \\
\hline RITZMANN (41) & 1967 & $\begin{array}{rr}196 & \\
\quad & 59,0 \\
\end{array}$ & $\begin{array}{rr}58 & \\
& 17,5\end{array}$ & $x$ & $\begin{array}{ll}61 & \\
& 18,4 \\
\end{array}$ & $\begin{array}{rr}17 & \\
& 5,1 \\
\end{array}$ & $x$ & $\begin{array}{rr}332 & \\
& 100,0 \\
\end{array}$ \\
\hline DAMMACCO U. WALDENSTRÖM (42) & 1968 & $\begin{array}{r}58 \\
\quad 59 \\
\end{array}$ & $\begin{array}{rr}23 & \\
\quad 24 \\
\end{array}$ & $\begin{array}{r}2 \\
\quad 2 \\
\end{array}$ & $\begin{array}{ll}10 & \\
\quad 10 \\
\end{array}$ & 5 & $x$ & $\begin{array}{r}98 \\
\quad 100 \\
\end{array}$ \\
\hline ROSER (43) & 1968 & $\begin{array}{ll}37 & \\
& 57 \\
\end{array}$ & $\begin{array}{r}22 \\
34\end{array}$ & $x$ & $\begin{array}{ll}4 & \\
& 6\end{array}$ & $x$ & $\begin{array}{r}2 \\
\quad 3 \\
\end{array}$ & $\begin{array}{r}65 \\
\quad 100 \\
\end{array}$ \\
\hline SCHEUERLEN (44) & 1969 & $\begin{array}{r}230 \\
\quad 59,3 \\
\end{array}$ & $\begin{array}{rr}66 & \\
& 17,0\end{array}$ & $x$ & $\begin{array}{rr}57 & \\
& 14,7\end{array}$ & $\begin{array}{rr}26 & \\
& \\
& 6,7 \\
\end{array}$ & $\begin{array}{ll}9 & \\
& \\
\cdot \quad 2,3 \\
\end{array}$ & $\begin{array}{l}388 \\
\therefore \quad 100,0 \\
\end{array}$ \\
\hline WEISE u. KESSEL (45) & 1969 & $\begin{array}{r}85 \\
\quad 60 \\
\end{array}$ & $\begin{array}{ll}37 & \\
& 26\end{array}$ & $x$ & $\begin{array}{ll}20 & \\
& 14 \\
& 14 \\
\end{array}$ & $x$ & $x$ & $\begin{array}{r}142 \\
100\end{array}$ \\
\hline FATEH et al. (46) & 1970 & $\begin{array}{rr}627 & \\
& 65,2 \\
\end{array}$ & $\begin{array}{ll}175 & \\
& 18,2 \\
& \end{array}$ & $x$ & $\begin{array}{rr}118 & \\
& 12,3 \\
& \end{array}$ & $\begin{array}{rr}29 & \\
& 3,0\end{array}$ & $\begin{array}{r}13 \\
\quad 1,3 \\
\end{array}$ & $\begin{array}{r}962 \\
\quad 100,0 \\
\end{array}$ \\
\hline Pruzanski u. Ogryslo' (47) & 1970 & $\begin{array}{rr}133 & \\
& 59 \\
\end{array}$ & $\begin{array}{ll}31 & \\
& 14 \\
\end{array}$ & $x$ & $\begin{array}{ll}24 & \\
& 11\end{array}$ & $\begin{array}{l}37 \\
\cdot 16 \\
\end{array}$ & $x$ & \begin{tabular}{|l}
225 \\
.$\quad 100$ \\
\end{tabular} \\
\hline Dugue et al. (48) & 1971 & $\begin{array}{rr}310 & \\
& 55,8 \\
\end{array}$ & $\begin{array}{ll}105 & \\
& 18,9 \\
\end{array}$ & 3 & $\begin{array}{rr}110 & \\
& 19,8 \\
\end{array}$ & $\begin{array}{r}27 \\
\quad 4,9 \\
\end{array}$ & $x$ & $\begin{array}{r}555 \\
\quad 100,0 \\
\end{array}$ \\
\hline Summe & & $\begin{array}{rr}4013 & \\
& 56,9\end{array}$ & $\begin{array}{r}1337 \\
18,9\end{array}$ & 11 & $\begin{array}{r}1229 \\
17,4\end{array}$ & $\begin{array}{ll}423 & \\
& 6,0\end{array}$ & $\begin{array}{ll}44 & \\
- & \\
& 0,6\end{array}$ & $\begin{array}{l}7057 \\
100,0\end{array}$ \\
\hline $\begin{array}{l}\text { Summe der Fälle von BACHMANN (25) } \\
\text { und von ZAWADSKI u. EDWARDS (38) }\end{array}$ & & $\begin{array}{rr}424 & \\
& 56,6 \\
\end{array}$ & $\begin{array}{rr}165 & \\
& 22,0\end{array}$ & 0,7 & $\begin{array}{rr}102 & \\
& 13,6 \\
\end{array}$ & 43 & $\begin{array}{ll}10 & \\
& 1,3\end{array}$ & $\begin{array}{l}749 \\
100,0\end{array}$ \\
\hline OBERDORFER et al. & 1973 & $\begin{array}{r}535 \\
\quad 63,9\end{array}$ & $\begin{array}{ll}144 & \\
& 17,2\end{array}$ & 0,8 & $\begin{array}{ll}106 & \\
& 12,7\end{array}$ & 31 & $\begin{array}{ll}14 & \\
& 1,7\end{array}$ & $\begin{array}{r}837 \\
100,0\end{array}$ \\
\hline
\end{tabular}

* LK $=$ Leichtkettenparaproteinämien

** MP = Mehrfachparaproteinämien

$x=$ Keine Angabe

In den Tabellenfeldern sind die Zahlen links oben absolute Fallzahlen, die Zahlen rechts unten Prozentwerte.

Tab. 10 Verteilung von Paraproteinämien nach Paraproteinämieklassen (IgG, IgA, LK*, MP**)

\begin{tabular}{|c|c|c|c|c|c|c|}
\hline \multirow{2}{*}{ Autor } & \multirow{2}{*}{$\begin{array}{c}\text { Jahr der } \\
\text { Veröffentlichung }\end{array}$} & \multicolumn{5}{|c|}{ Paraproteinämieklasse } \\
\hline & & IgG & IgA & LK* & MP** & Summe \\
\hline 1. Drivsholm u. Clausen (15) & 1964 & $\begin{array}{rr}67 & \\
& 64 \\
\end{array}$ & 25 & 7 & 4 & $\begin{array}{rr}104 & \\
& 100 \\
\end{array}$ \\
\hline 2. OSSERMANN (34) & 1965 & $\begin{array}{|ll|}142 & \\
& \\
& 55 \\
\end{array}$ & 22 & 23 & $x$ & 100 \\
\hline 3. LAURELL u. SNIGUROWICZ (49) & 1967 & 70,4 & 22,8 & 6,0 & 0,8 & 100,0 \\
\hline 4. CARBone et al. (19) & 1967 & $\begin{array}{|ll|}63 & \\
& \\
& 70 \\
\end{array}$ & 20 & 10 & $x$ & $\begin{array}{cc}90 & \\
\cdot & \\
& 100 \\
\end{array}$ \\
\hline 5. НоввS (27) & 1969 & \begin{tabular}{|l}
112 \\
\\
\end{tabular} & $\begin{array}{r}54 \\
\\
\quad \quad 26 \\
\end{array}$ & 40 & $x$ & $\begin{array}{rr}206 & \\
& 100 \\
\end{array}$ \\
\hline Summe von 1. bis 5 . & & 63,5 & 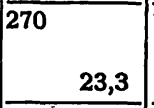 & $\begin{array}{r}12,6 \\
\end{array}$ & 0,6 & $\begin{array}{ll}1159 & \\
& 100,0 \\
& \end{array}$ \\
\hline Summe von 1 . und 3. & $\therefore$ & 69,4 & 23,2 & 6,3 & 1,1 & $\begin{array}{rr}604 & \\
& 100,0 \\
\end{array}$ \\
\hline OBERDORFER et al. & 1973 & 73,9 & 19,9 & 4,3 & 1,9 & 100,0 \\
\hline
\end{tabular}

* LK = Leichtkettenparaproteinämien

** MP $=$ Mehrfachproteinămien

In den Tabellenfeldern sind die Zahlen links oben absolute Fallzahlen, die Zahlen rechts unten Prozentwerte. 
Obersicht 1

Kasuistik von Mehrfachparaproteinămien

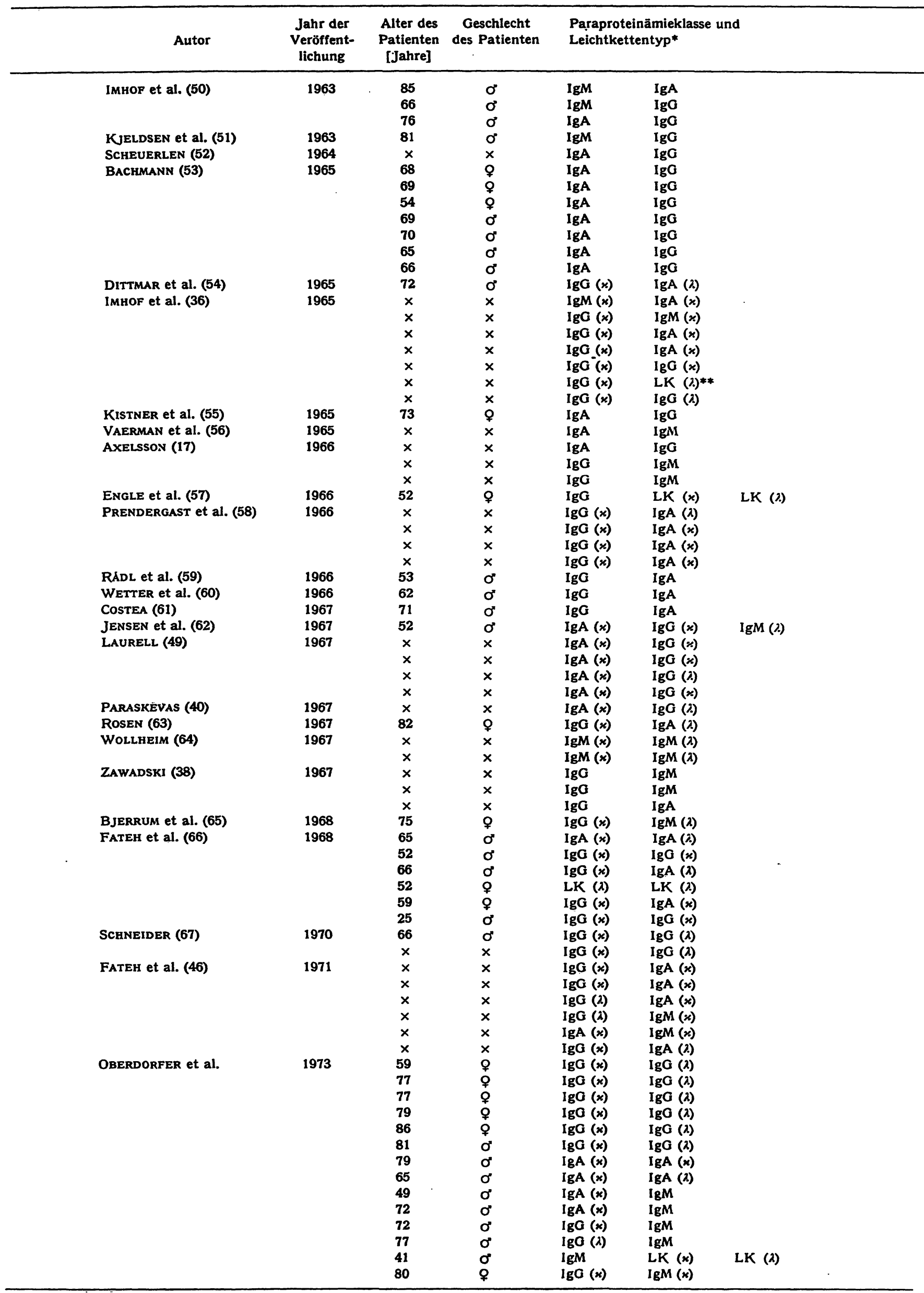

- Soweit von den Autopren mitgeteilt

* LK = Leichtkettenparaproteinåmie

$x=$ Keine Angabe 
Die im eigenen Material und im ParaproteinämieMaterial anderer Autoren vorliegenden Verteilungen nach dem Leichtketten-Typ sind aus Tabelle 11, die entsprechenden Kappa: Lambda-Verhältnisse aus Tabelle 12 ersichtlich. Sowohl im eigenen Gesamtmaterial, als auch im Gesamtmaterial anderer Autoren überwiegt der Kappa-Typ.

Die Konfidenzintervalle der Kappa:Lambda-Verhältnisse von IgG-, IgA- und IgM-Paraproteinämien (des eigenen Materials und des Materials anderer Autoren) sind in den Abbildungen 2 bis 4 graphisch dargestellt. Die Länge der Konfidenzintervalle hängt in starkem Maße von der jeweiligen Fallzahl ab. Bei geringen Fallzahlen sind die Konfidenzintervalle groß, bei großen Fallzahlen klein. Bei IgG-Paraproteinämien liegt das im normalen Serum-IgG-Globulin vorliegende Kappa: Lambda-Verhältnis von 2,2:1 außerhalb der Konfidenzintervalle des Paraproteinämiematerials' von Autoren mit großen Fallzahlen.

Tab. 11 Verteilung von Paraproteinämien nach Leichtkettentypen

\begin{tabular}{|c|c|c|c|c|c|c|c|c|c|c|c|c|}
\hline \multirow{2}{*}{ Autor } & \multirow{2}{*}{$\begin{array}{c}\text { Jahr der } \\
\text { Veröffent- } \\
\text { lichung }\end{array}$} & \multicolumn{5}{|c|}{ Kappa } & \multicolumn{5}{|c|}{ Lambda } & \multirow{2}{*}{ Summe } \\
\hline & & $\lg G$ & IgA & $\operatorname{Ig} M$ & LK* & Summe & IgG & IgA & $\operatorname{Ig} M$ & LK* & Summe & \\
\hline $\begin{array}{l}\text { FAHEY U. SOLOMON } \\
\text { (33) }\end{array}$ & 1963 & 67 & $\begin{array}{ll}11 \\
\\
\end{array}$ & 82 & 16 & 89 & 33 & 50 & 18 & 14 & $\begin{array}{ll}51 & \\
& 36\end{array}$ & 140 \\
\hline IMHOF et al. (36) & 1965 & $\begin{array}{ll}71 & \\
& 61 \\
\end{array}$ & 60 & 66 & 57 & 149 & $\begin{array}{ll}45 & \\
& 39 \\
\end{array}$ & 40 & 34. & 9 & 93 & 242 \\
\hline $\begin{array}{l}\text { ZAWADSKI u. } \\
\text { EDWARDS (38) }\end{array}$ & 1966 & 62 & 31 & 17 & 63 & 111 & 38 & 22 & $\begin{array}{ll}5 & \\
& 83\end{array}$ & 9 & 76 & 187 \\
\hline Carbone et al. (19) & 1967 & $\begin{array}{ll}45 & \\
& \\
& 71 \\
\end{array}$ & 72 & $x$ & $\begin{array}{ll}4 & \\
& 44 \\
\end{array}$ & 67 & 29 & 28 & $x$ & 56 & 33 & 90 \\
\hline $\begin{array}{l}\text { LAURELL U. } \\
\text { SNIGUROWICZ (49) }\end{array}$ & 1967 & 65 & 54 & $x$ & 57 & 301 & 35 & 60 & $x$ & 43 & 195 & 496 \\
\hline $\begin{array}{l}\text { WOLLHEIM u. } \\
\text { SNIGUROWICZ (64) }\end{array}$ & 1967 & $x$ & $x$ & 80 & $x$ & $\begin{array}{rr}100 & \\
& 80 \\
& \\
\end{array}$ & $x$ & $x$ & 20 & $x$ & 20 & 125 \\
\hline $\begin{array}{l}\text { DAMMACCO U. } \\
\text { WALDENSTRÖM (42) }\end{array}$ & 1968 & 69 & 26 & 70 & 60 & 58. & 31 & 74 & 30 & 40 & 40 & 96 \\
\hline FATEH et al. (46) & 1970 & 62 & 52 & 80 & 63 & 62 & 38 & 48 & 20 & 37 & 260 & 691 \\
\hline Dugue et al. (48) & 1971 & 59 & 32 & 80 & 32 & $\overline{171}$ & 41 & 36 & 20 & 68 & 40 & 287 \\
\hline OBERDORFER et al. & 1973 & 57 & 55 & 73 & 43 & 57 & 43 & 45 & 27 & 57 & 278 & 658 \\
\hline
\end{tabular}

* LK = Leichtkettenparaproteinämien

$x=$ Keine Angabe

In den Tabellenfeldern sind die Zahlen links oben absolute Fallzahlen, die Zahlen rechts unten Prozentwerte.

Tab. 12 Kappa-Lambda-Verhältnis von Paraproteinämien innerhalb von Paraproteinklassen

\begin{tabular}{|c|c|c|c|c|c|c|c|c|c|c|c|c|}
\hline \multirow[t]{2}{*}{ Autor } & \multirow{2}{*}{$\begin{array}{l}\text { Jahr der } \\
\text { Veröffent- } \\
\text { lichung }\end{array}$} & \multirow[t]{2}{*}{$\begin{array}{l}\text { Fall- } \\
\text { zahl }\end{array}$} & \multicolumn{2}{|c|}{ IgG } & \multicolumn{2}{|c|}{ IgA } & \multicolumn{2}{|c|}{ IgM } & \multicolumn{2}{|c|}{ LK* } & \multicolumn{2}{|c|}{$\begin{array}{l}\text { Gesamt- } \\
\text { material }\end{array}$} \\
\hline & & & Kappa & Lambda & Kappa & Lambda & Kappa & Lambda & Kappa & Lambda & Kappa & Lambda \\
\hline FAHEY U. SOLOMON (33) & 1963 & 140 & 2,0 & 1 & 1,0 & 1 & 4,5 & 1 & 1,1 & 1 & 1,7 & 1 \\
\hline IMHOF et al. (36) & 1965 & 242 & 1,6 & 1 & 1,5 & 1 & 1,9 & 1 & 1,3 & 1 & 1,6 & 1 \\
\hline ZAWADSKI U. EDWARDS (38) & 1966 & 187 & 1,6 & 1 & 1,4 & 1 & 0,2 & 1 & 1,7 & 1 & 1,5 & 1 \\
\hline CARBONE et al. (19) & 1967 & 90 & 2,5 & 1 & 2,6 & 1 & $x$ & $x$ & 0,8 & 1 & 2,2 & $i$ \\
\hline LAURELL U. SNIGUROWICZ (49) & 1967 & 496 & 1,9 & 1 & 0,9 & 1 & $x$ & $x$ & 1,3 & 1 & 1,5 & 1 \\
\hline WOLLHEIM น. & & & & & & & & & & & & \\
\hline $\begin{array}{l}\text { SNIGUROWICZ (64) } \\
\text { DAMMACCO u. }\end{array}$ & 1967 & 125 & $x$ & $x$ & $\times$ & $x$ & 4,0 & 1 & $x$ & $x$ & 4,0 & 1 \\
\hline WALDENSTRÖM (42) & 1968 & 96 & 2,2 & 1 & 0,4 & 1 & 2,3 & 1 & 1,5 & 1 & 1,4 & 1 \\
\hline FATEH et al. (46) & 1971 & 691 & 1,7 & 1 & 1,0 & 1 & 4,0 & 1 & 1,7 & 1 & 1,7 & 1 \\
\hline SNAPPER U. KAHN (28) & 1971 & 218 & 1,8 & 1 & 1,0 & 1 & 3,0 & 1 & $x$ & $x$ & $x$ & $x$ \\
\hline Dugue et al. (48) & 1971 & 287 & 1,4 & 1 & 1,7 & 1 & 4,0 & 1 & 0,5 & 1 & 1,5 & 1 \\
\hline OBERDORFER et al. & 1973 & 506 & 1,4 & 1 & 1,2 & 1 & 2,4 & 1 & 0,8 & 1 & 1,3 & 1 \\
\hline
\end{tabular}

* LK = Leichtkettenparaproteinämien

$x=$ Keine Angabe 


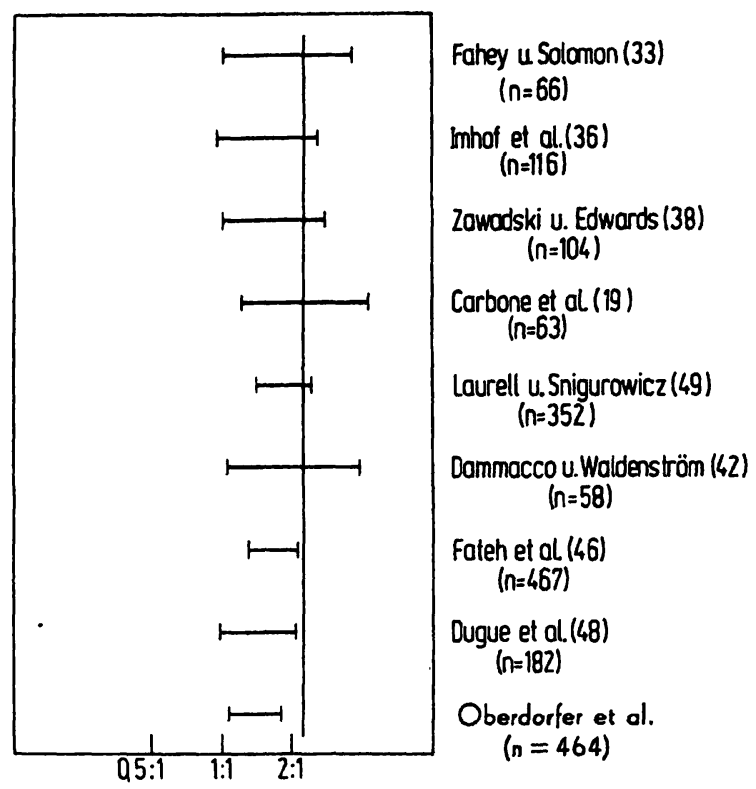

Abb. 2

99\%-Konfidenzbereiche des Kappa:Lambda-Verhältnisses von IgGParaproteinämien. Das von FAHEY (68) für IgG im Serum Gesunder angegebene Kappa:Lambda-Verhältnis von 2,2:1 ist als senkrechter Strich eingezeichnet. Die Länge der Konfidenzbereiche hängt im Wesentlichen von der Fallzahl n ab

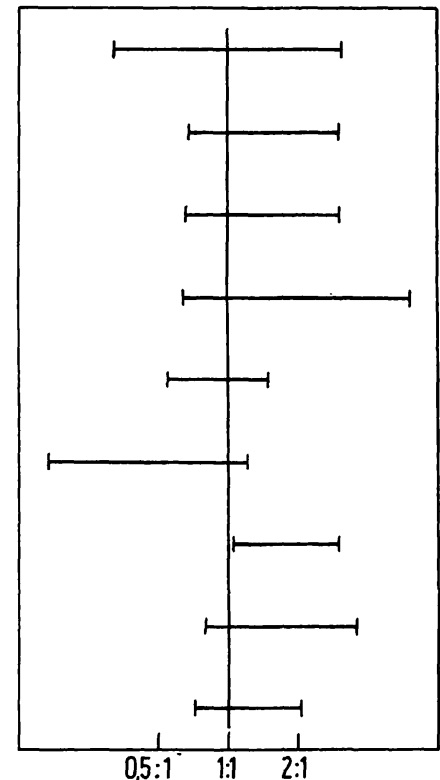

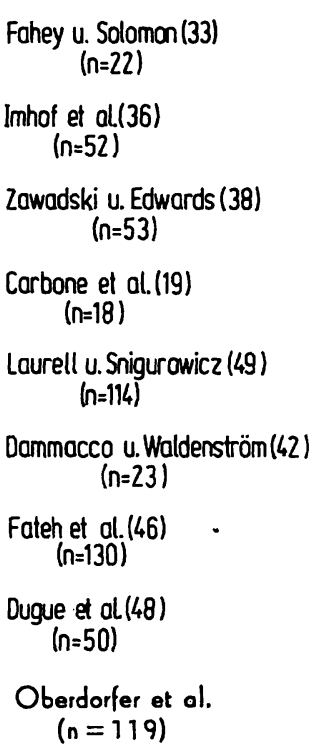

Abb. 3

99\%-Konfidenzbereiche des Kappa: Lambda-Verhältnisses von IgAParaproteinämien. Das von FAHEY (68) für IgA im Serum Gesunder angegebene Kappa-Lambda-Verhältnis von $1: 1$ ist als senkrechter Wesentlichen von der Fallzahl $\mathbf{n}$ ab

Dieses Resultat widerspricht der von FaTEH et al. (46) aufgestellten Behauptung, daß die Kappa:Lambda-Verteilung der IgG-Paraproteinämien mit der des normalen IgG-Globulins ,identisch“ sei. Bei IgM-Paraproteinämien überdecken die Konfidenzintervalle der Paraproteinämie-Materialien von Autoren mit relativ kleinen Fallzahlen das im normalen Serum-IgM-Globulin vorliegende Kappa:Lambda-Verhältnis von 2:1. Das Konfidenzintervall des IgM-Paraproteinämie-Materials von Wollheim (64), des Materials mit der größten Fallzahl von IgM-Paraproteinämien, liegt außerhalb des hypothetischen Wertes von 2:1 (Abb. 4).

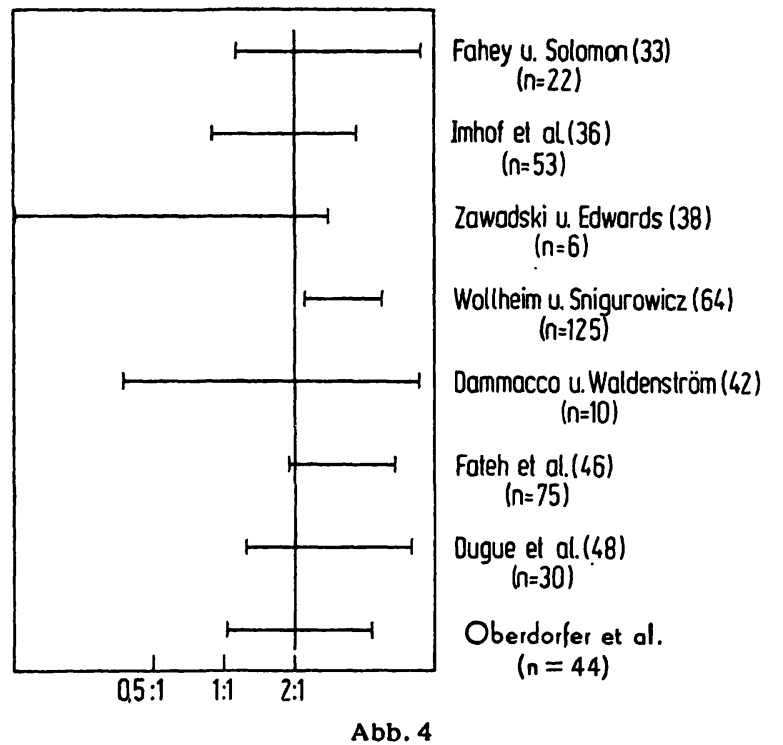

$99 \%$-Konfidenzbereiche des Kappa:Lambda-Verhältnisses von IgMParaproteinämien. Das von FAHEY (68) für IgM im Serum Gesunder angegebene Kappa:Lambda-Verhältnis von $2: 1$ ist als senkrechter
Strich eingezeichnet. Die Länge der Konfidenzbereiche hängt im Wesentlichen von der Fallzahl $n$ ab

An dieser Stelle sei auf die methodische Problematik hingewiesen, die sich bei der Leichtkettenbestimmung von IgM-Paraproteinämien ergibt. Während bei der Leichtkettenbestimmung der IgG-, IgA- und IgD-Paraproteinämien keine methodischen Schwierigkeiten auftreten, gelingt die „direkte“ Leichtkettenbestimmung bei IgM-Paraproteinämien nur in einem Teil der Fälle. Bei unserem Material konnten von 71 auf LeichtkettenTyp untersuchten IgM-Paraproteinämien nur 37 Fälle durch direkte Typenbestimmung differenziert werden. FAHEY und Solomon (33) konnten von 22 untersuchten IgM-Paraproteinämien 12 Fälle nach dem LeichtkettenTyp direkt differenzieren. Das Material von Fater et al. (46) enthält einen höheren Anteil an direkt differenzierbaren IgM-Paraproteinämien: Von 75 untersuchten Fällen wurden 66 direkt differenziert, 9 nach Spaltung der Moleküle.

Als „direkte“ Leichtkettenbestimmung wird hier die in unvorbehandeltem Serum durchgeführte Typenbestimmung bezeichnet. Ein Teil der IgM-Paraproteine hat anscheinend nicht genügend Leichtketten-Determinanten an der Moleküloberfläche. Erst nach Spaltung dieser Moleküle in kleinere Untereinheiten werden die „hidden antigens" zugänglich, so daß dann die Typenbestimmung gelingt.

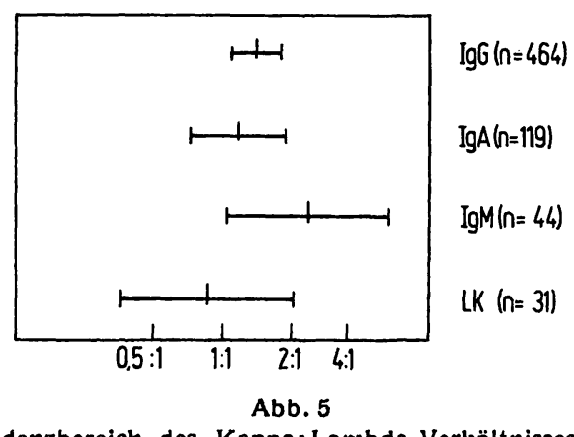

$99 \%$-Konfidenzbereich des Kappa: Lambda-Verhältnisses von IgGIgA-, IgM- und Leichtketten-Paraproteinämien des eigenen Materials. Die beobachteten Verhältniswerte sind innerhalb des Konfidenzbereiches durch einen senkrechten Strich markiert 
Abbildung 5 zeigt, daß sich die Konfidenzintervalle der Kappa:Lambda-Verhältnisse der einzelnen Paraproteinämieklassen des eigenen Materials überschneiden. Die $\chi^{2}$-Prüfung ergibt hinsichtlich der Kappa:LambdaVerteilung keine statistisch gesicherten Unterschiede zwischen den Paraproteinämieklassen.

Ǔbersicht 2 läßt im Material aller Autoren ein ausgeprägtes Überwiegen der $\operatorname{IgD}$-Paraproteinämien mit Leichtketten vom Lambda-Typ erkennen. Auch bei den IgD-Paraproteinämien des eigenen Materials überwiegen die Fälle mit Leichtketten vom Lambda-Typ. Wie oben erwähnt, unterscheidet sich das Kappa:Lambda-Verhältnis der IgD-Paraproteinämien unseres Materials jedoch nicht signifikant von der Leichtkettenverteilung in den übrigen Paraproteinämieklassen. Dieses Testergebnis dürfte wahrscheinlich durch die geringe Anzahl von IgD-Paraproteinämien im eigenen Material bedingt sein.

Das Kappa:Lambda-Verhältnis der Leichtkettenparaproteinämien des eigenen Materials ist zugunsten des Lambda-Typs verschoben (siehe Tabelle 12). Auch im Material von PARASKevas (40) und im Material von Dugue et al. (48) überwiegen die Leichtketten-Paraproteinämien vom Lambda-Typ. Die Verteilung der IgG-Paraproteinämien unseres Materials nach IgGSubklassen entspricht den von SkVARIL et al. (10) und TERRY et al. (89) mitgeteilten IgG-Subklassenverteilungen. Das Kappa:Lambda-Verhältnis in der Subklasse IgG3 unseres Materials (Kappa:Lambda $=3: 8$ ) unterscheidet sich auffällig vom Kappa:Lambda-Verhältnis dieser Subklasse im Material von SkvarIL et al. (10) (Kappa:Lambda $=29: 13$ ). In dieșer Subklasse weist

Ubersicht 2

Kasuistik von IgD-Paraproteinämien

\begin{tabular}{|c|c|c|c|c|c|c|c|}
\hline & Autor & $\begin{array}{c}\text { Jahr der } \\
\text { Veröffentlichung }\end{array}$ & $\begin{array}{c}\text { Leicht- } \\
\text { kettentyp }\end{array}$ & $\begin{array}{l}\text { Geschlecht } \\
\text { des Patienten }\end{array}$ & $\begin{array}{c}\text { Alter } \\
\text { des Patienten } \\
\text { [Jahre] }\end{array}$ & & \\
\hline & RòW่E u. FAHEY (69) & 1965 & $\lambda$ & $\sigma^{\prime \prime}$ & 57 & & \\
\hline \multirow{46}{*}{ - } & BURTIN et al. (70) & 1966 & $\lambda$ & $\sigma^{\prime \prime}$ & 53 & & \\
\hline & & & $\lambda$ & 우 & 55 & & \\
\hline & HOBBs et al. (71) & 1966 & $\lambda$ & $\stackrel{+}{+}^{+}$ & 42 & & \\
\hline & & & $\lambda$ & ơ & 40 & & \\
\hline & & & $\lambda$ & $\sigma^{\prime \prime}$ & 43 & & \\
\hline & & & $\lambda$ & $0^{\pi}$ & 53 & . & \\
\hline & & & $\lambda$ & $0^{\prime \prime}$ & 56 & & \\
\hline & & & $\lambda$ & $0^{\circ}$ & 44 & & \\
\hline & VENTRUTO U. QUATTRIN (72) & 1966 & $\lambda$ & o & $x$ & & \\
\hline & BACHMANN (73) & 1967 & $\lambda$ & $0^{+}$ & 66 & & \\
\hline & & & $\lambda$ & $\sigma^{\prime \prime}$ & 74 & & \\
\hline & & & $\lambda$ & o & 47 & & . \\
\hline & & & $\lambda$ & \begin{tabular}{l}
+ \\
\hdashline
\end{tabular} & 75 & & \\
\hline & & & $\lambda$ & \% & 67 & & \\
\hline & & & $\lambda$ & ơ & 58 & & \\
\hline & & & $\lambda$ & $0^{+}$ & 50 & & \\
\hline & & & $\lambda$ & $0^{\pi}$ & 57 & & \\
\hline & KLEMM et al. (74) & 1967 & $\lambda$ & 우 & 58 & & \\
\hline & LAURELL U. SNIGUROWICZ (49) & 1967 & $\lambda$ & $x$ & $x$ & & \\
\hline & & & $\lambda$ & $x$ & $x$ & & \\
\hline & & & $\lambda$ & $x$ & $x$ & & \\
\hline & & & $\lambda$ & $x$ & $x$ & & \\
\hline & MASAKI et al. (75) & 1967 & $\lambda$ & $x$ & $x$ & & 。 \\
\hline & MEISER U. HUHNSTOCK (39) & 1967 & $\lambda$ & $\hat{q}$ & $\hat{x}$ & & \\
\hline & SCHNEIDER (76) & 1967 & $\ddot{x}$ & $\begin{array}{l}\text { f } \\
\text { q }\end{array}$ & $\hat{53}$ & & \\
\hline & SPENGLER et al. (77) & 1967 & $\lambda$ & $\stackrel{+}{+}$ & 55 & & \\
\hline & WIEDERMANN et al. (78) & 1967 & $\ddot{\lambda}$ & $\begin{array}{l}7 \\
0^{\prime \prime}\end{array}$ & 73 & & \\
\hline & & & $\lambda$ & Q & 55 & & \\
\hline & ZAWADSKI U. RUBINI (79) & 1967 & x & $\sigma^{\circ}$ & 71 & & \\
\hline & & & x & $0^{\prime \prime}$ & 58 & & \\
\hline & BEN-BASSAT et al. (80) & 1968 & $\lambda$ & 오 & 69 & & \\
\hline & BERT u. FoNTANA (81) & 1968 & $\lambda$ & $\sigma^{*}$ & 71 & & \\
\hline & DAMMACCO U. BONOMO (82) & 1968 & $x$ & $\sigma^{\prime \prime}$ & 55 & & \\
\hline & FAHEY et al. (83) & 1968 & $\lambda$ & $\sigma^{\prime \prime}$ & 58 & & \\
\hline & & & $\lambda$ & 0 & 66 . & & \\
\hline & & & $\lambda$ & 운 & 59 & & \\
\hline & & & $\lambda$ & $\overbrace{}^{+}$ & 42 & & \\
\hline & & & $\lambda$ & $\sigma^{\prime \prime}$ & 45 & & \\
\hline & & & $\boldsymbol{x}$ & $\sigma^{\prime \prime}$ & 40 & & \\
\hline & & & $\lambda$ & o & 43 & & \\
\hline & & & $\lambda$ & $\sigma^{+}$ & 65 & & \\
\hline & & & $\lambda$ & 우 & 55 & & \\
\hline & & & $\boldsymbol{x}$ & $\sigma^{\prime \prime}$ & 53 & & \\
\hline & & & $\lambda$ & $\sigma^{\prime \prime}$ & 48 & & \\
\hline & & & $\lambda$ & $\sigma^{\prime \prime}$ & 41 & & \\
\hline & & . & $x$ & o & 47 & & \\
\hline
\end{tabular}




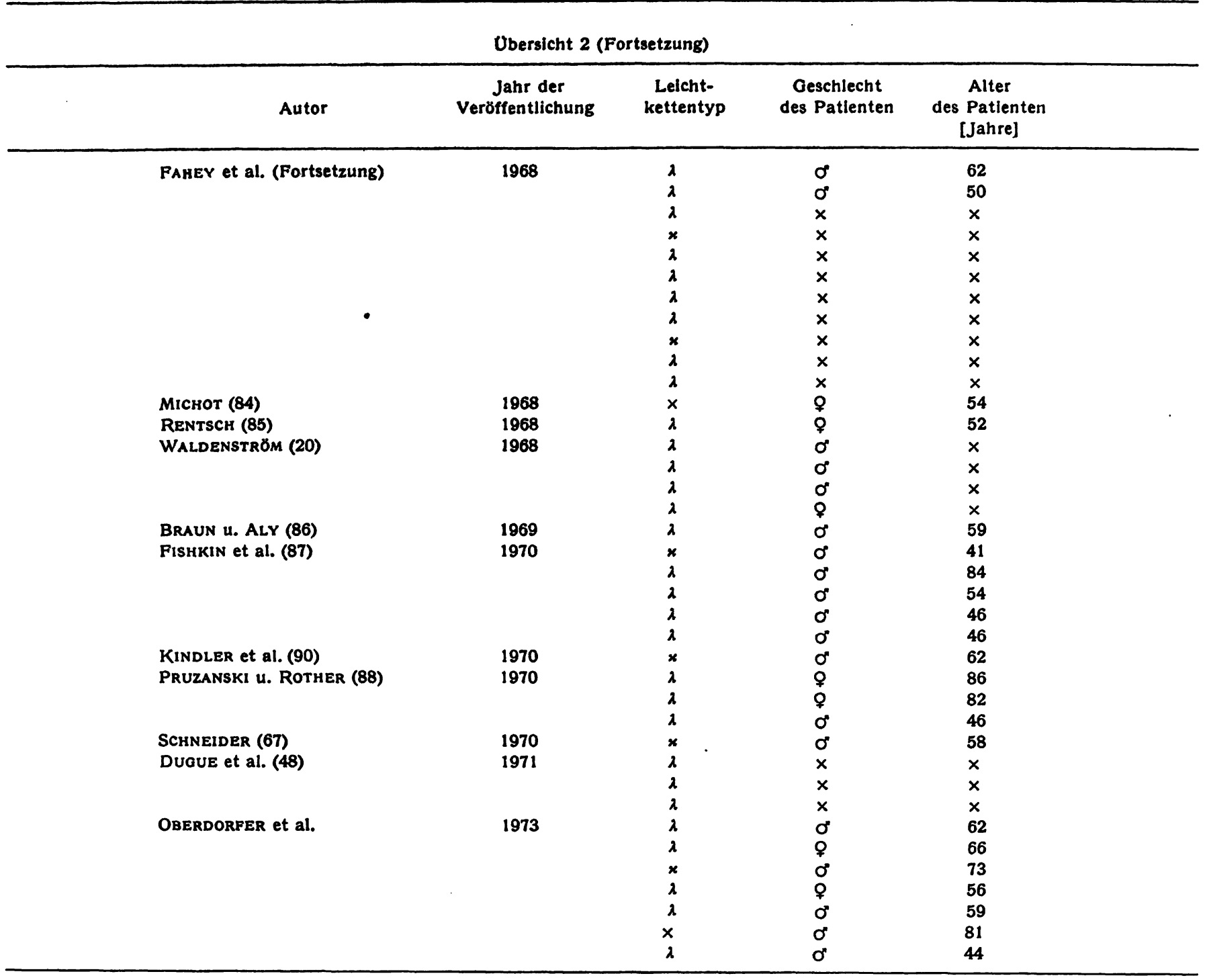

$x=$ keine Angabe

also unser Paraproteinämiematerial mehr Fälle mit Lambdaketten auf, während im Paraproteinämiematerial von SKvarIL et al. (10) auch in dieser Subklasse die Fälle mit Leichtketten vom Kappa-Typ überwiegen. Sowohl im eigenen Material als auch im Paraproteinämiematerial von SKvariL et al. (10) ist das Überwiegen der Fälle mit Leichtketten vom Kappa-Typ in der Subklasse IgG4 am stärksten ausgeprägt (eigenes Material: Kappa: Lambda $=9: 1$, Material von Skvaril et al. (10): Kappa:Lambda $=18: 6$ ). Gegenüber dem Paraprotein- ämiematerial von TERRY et al. (89) unterscheidet sich unser Material bezüglich des Kappa:Lambda-Verhältnisses in den IgG-Subllassen nicht wesentlich.

\section{Danksagung}

Für die Durchführung der Subklassenbestimmungen danken wir Herrn Dr. F. Skvaril (Institut für klinisch-experimentelle Tumorforschung der Universität Bern). Für die Mithilfe bei der technischen Durchführung der statistischen Berechnungen und für das Schreiben der Tabellen danken wir der Dokumentationsassistentin Ftäulein U. HoffMaNN.

\section{Literatur}

1. Weichselbaum, T. E. (1946), Amer. J. Clin. Pathol. Techn. Sect. 10, 40-49. - 2. Grabar, P. \& Williams, C. A. (1953), Biochim. Biophys. Acta 10, 193-194. - 3. GrABAR, P. \& Wirliams, C. A. (1955), Biochim. Biophys. Acta 17, 67-74. 4. Scheidegger, J. J. (1955), Int. Arch. Allerg. Appl. Immunol. 7, 103-110. - 5. Grabar, P., FAuVert, R., Burtin, P. \& HARTMANN, L. (1956), Rev. Fr. Etud. Clin. Biol. 1, 175-186. - 6. Burtin, P., Hartmann, L., Heremans, J. F., Scheidegger, J. J., Wesendorp-Boerma, F., WiEme, R., Wunderly, Ch., Fauvert, R. \& Grabar, P. (1957), Rev. Fr. Etud. Clin. Biol. 2, 5-177. - 7. Heremans, J. F. \& Heremans, M. Th. (1958), Proc. 7th. Congr. Intern. Soc. Haematol., Roma. - 8. Heremans, J. F. (1963), Ergebn. Inn. Med. Kinderh. NF 20, 189-257. 9. Ouchterlony, O. (1953), Acta Pathol. Microbiol. Scand. 32,
231-240. - 10. Skvarid, F., Morell, A. \& Barandun, S. (1971), Vox Sang. 23, 546-551. - 11. Dokumenta GergY (1968), Wissenschaftliche Tabellen, 7. Auf., S. 85-103, J. R. Geigy AG, Pharma, Basel. - 12. Heinhold, J. \& GAEDE, K. W. (1968), Ingenieur-Statistik 2. Aufl,, S. 173, Verlag Oldenbourg, München. - 13. Martin, N. H. (1961), Lancet I, 237-239. 14. InNES, J. \& Newall, J. (1961), Lancet I, 239-245. - 15. Drivsholm, A. \& Clausen, J. (1964), Acta Med. Scand. 175, 609-620. - 16. Riva, G. (1964), Helv. Med. Acta 4/5, 285-297. 17. Axelsson, U., Bacimann, R. \& Hällén, J. (1966), Acta Med. Scand. 179, 235-247. - 18. Hällén, J. (1966), Acta Med. Scand. Suppl. 462, 8-127. - 19. Carbone, P. P., Kellerhouse, L. E. \& Gehan, E. A. (1967), Amer. J. Med. Sci. 42, 937-948. 20. Waldenström, J. (1968), Monoclonal and polyclonal Hyper- 
gammaglobulinaemia Cambridge University Press. - 21. KyLE, R. A., Nobrega, F. T. \& Kurland, L. T. (1969), Blood 33, 739745. - 22. Isobe, T. \& Ossermann, E. F. (1971), Ann. N. Y. Acad. Sci. 190, 507-518. - 23. Geschickter, C. F. \& Copeland, M. M. (1928), Arch. Surg. 10, 807-862. - 24. BACHMANN, R. \& Laurell,.C. B. (1963), Scand. J. Clin. Lab. Invest. 15, 11-24. 25. Bachmann, R. (1965), Acta Med. Scand. 178, 801-808. 26. KNedel, M., Fatem-Moghadam, A. \& Lamerz, R. (1968), Arch. Klin. Med. 215, 311-339. - 27. Hоввs, J. R. (1969), Brit. J. Haematol. 16, 599-606. - 28. SNAPPER, I. \& KAFN, A. (1971), in Myelomatosis. Fundamentals and clinical features, Verlag Karger, Basel-München. - 29. Heremans, J. F. (1961), Bull. Schweiz. Akad. Med. Wiss. 17 (Suppl.), 119 bis 138. 30. Waldenström, J. (1961), Acta Med. Scand. Suppl. 367, 110-119. - 31. Roulet, D. L. A., Spengler, G. A. \& Hüssig, A. (1962), Vox Sang. 7, 281-297. - 32. Creyssel, R., Groulade, J., Fine, J. M. \& Beturl, H. (1964), in Protides of the biological Fluids, (Peeters, H., Hrsg.) S. 97-99, Elsevier, Amsterdam. - 33. FAHEY, J. L. \& Solomon, A. (1963), J: Clin. Invest. 42, 811-822. - 34. OssermanN, E. F. (1965), in "Immunological Diseases“ (SAmten \& Alexander ed.) S. 353-363, Verlag J. u. A. Churchill, London. - 35. KLemM, D. (1966), Fortschr. Med. 84, 941-944. - 36. IMнoF, J. W., Ballieux, R. E., Mul, N. A. \& Poen, H. (1965), Acta Med. Scand. Suppl. 441, 102-108. - 37. ScheuerLeN, P. G. (1966), Ärztl. Fortb. 2, 68-71. - 38. ZaWAdSKI, Z. A. \& EdwardS, G. A. (1967), Amer. J. Clin. Pathol. 48, 418-430. - 39. Merser, J. \& Huhnstock, K. (1967), Verh. Deut. Ges. Inn. Med. 73, 821-824. - 40. Paraskevas, F. (1967), Clin. Biochem. 1, 135-153. 41. Rutzmani, S. E. \& Levin, W. C. (1967), Lab. Synopsis 2, 9-13. - 42. Dammacco, F. \& Waldenström, J. (1968); Acta Med. Scand. 184, 403-409. - 43. Roser, H. (1968), Deut. Med. Wochenschr. 93, 1324-1326. - 44. ScheuERLEN, P. G. (1969), Sonderdruck aus Forts. d. Krebsforschung (ScFMrd, C. G. \& WeTter, O. ed.), S. 398-412. FK Schattauer, Verlag, StuttgartNew York. - 45. Werse, W. \& Kessel, M. (1969), Verh. Deut. Ges. Inn. Med. 75, 689-692. - 46. FATEH-MoghadAM, A., Lamerz, R., KNedeL, M. \& Tsirimbas, B. (1971), Klin. Wochenschr. 49, 458-467. - 47. Pruzanski, W. \& Ogryzlo, M. A. (1970), Adv. Clin. Chem. 13, 335-382. - 48. Dugue, M., Rousselet, F., KahN, M. F. \& Grrard, M. L. (1971), Clin. Chim. Acta 33, 75-86. - 49. Laurell, C. B. \& Singurowicz, J. (1967), Scand. J. Haematol. 4, 46-52. - 50. IмноF, J. W. \& Ballieux, R. E. (1963), in Proc. 9. Congr. Soc. Haemat. Lisbon, S. 1597-1599, Verlag S. Karger, Basel/New York. 51. KJeldsen, K. \& Asfeldt, V. H. (1963), Acta Med. Scand. 174, 407-413. - 52. Scheuerlen, P. G. (1964), Deut. Med. Wochenschr. 89, 42-45. - 53. BACHMANN, R. (1965), Acta Med. Scand. 177, 593-599. - 54. Dittmar, K., Kochowa, S., ZuCker-Franklin, D., Gralnich, H. \& Wasseriman, L. R. (1968), Blood 26, 881. - 55. Kistner, S. \& Norberg, R. (1965), Scand. J. Clin. Lab. Invest. 17, 321-324. - 56. Vaerman, J. P.,
Johnson, L. B., Mandy, W. \& Fudenberg, H. H. (1965), J. Lab. Clin. Med. 65, 19-25 - 57. Engle, R. L. jr. \& Nachman, R. L. (1966), Blood 27, 74-77. - 58. Prendergast, R. A., Grey, H. M. \& KunkeL, H. G. (1966), J. Exp. Med. 124, 185-197. - 59. RAdr, J., Chotт, L. \& RrhovA, D. (1966), Klin. Wochenschr. 44, 1117-1119. - 60. WETTER, O. \& HeRTENSTEIN, C. H. (1966), Klin. Wochenschr. 44, 1111-1117. 61. Costea; N., Yakulis, V. J., Libnoch, J. A., Pilz, C. G. \& Heller, P. (1967), Amer. J. Med. 42, 630-635. - 62. Jensen, K., Jensen, K. B. \& Oelsen, H. (1967), Scand. J. Haemiatol. 4, 485-488. - 63. Rosen, B. J., SmITH, T. W. \& BLOCH, K. J. (1967), N. Engl. J. Med. 277, 902-907. - 64. Wollferm, F. A. \& Snigurowicz, J. (1967), Scand. J. Haematol. 4, 111-117. 65. Bjerrum, O. E. \& WeEke, B. (1968), Scand. J. Haematol. 5, 215-234. - 66. Fateh-Moghadam, A., Würz, H., Oeser, R. M. \& KNeDEL, M. (1968), Deut. Med. Wochenschr. 36, 1695-1702. - 67. SChNEIDER, W. (1970), Blut 20, 4-13. 68. FAHEY, J. L. (1965), J. Amer. Med. Ass. 194, 183-186. 69. Rowe, D. S. \& FAhEX, J. I. (1965), J. Exp. Med. 121, 171-184. - 70. Burtin, P., Guilbert, B. \& BufFe, D. (1966), Clin. Chim. Acta 13, 675-677. - 71. Новвs, J. R., SLot, G. M., Campbeli, C. H., Clein, G. P., Scotr, J. T., CRowther, D. \& SWAN, H. T. (1966), Lancet II, 614-618. - 72. Ventruto, V. \& Quatrrin, N. (1966), Haematologica 51, 545-552. - 73. BachmanN, R. (1967), Nobel Symp. 3, 605-614. - 74. KIEMM, D., Schubothe, H., Heimper, H. \& Kasemir, H. D. (1967), Klin. Wochenschr. 45, 590-591. - 75. MASAKx, A., DANBARA, C., Harada, H., Teramura, F., Sanada, I., Takata, T. \& Shinozaki, K. (1967), Acta Haematol. Jap. 30, 475-482. - 76. ScHNEIDER, W. (1967), Deut. Med. Wochenschr. 92, 2172 - 2174. - 77. Spengler, G. A., Bütler, R., Pflugshaupt, R., Lopez, V. \& Barandum, S. (1967), Schweiz. Med. Wochenschr. 97, 170-178. 78. WIedermanN, D̃., WIEDERMANN, B., RAdL, J., Skvarit, F. \& VAerman, J. P. (1967), Schweiz. Med. Wochenschr. 97, 207-210. 79. Zawadski, Z. A. \& RubinI, J. R. (1967); Atch. Intern. Med. 119, 387-393. - 80. BEN-BASSAT, İ., FRAND, U. I., ISERSKY, C. \& Ramot, B. (1968), Arch. Intern. Med. 121, 361-364. - 81. Bert, G. \& Fontana, F. (1968), Btit. Med. J. 2, 117. - 82. Dammacco, F. \& Bonomo, L. (1968), Scand. J. Haematol. 5, 161-170. - 83. Fahey, L. J., Carbone, P. P., Rowe, D. S. \& BachmanN, R. (1968), Amer. J. Med. 45, 373-380. - 84. Mrснот, F. (1968), Schweiz. Med. Wochenschr. 98, 1598-1602. 85. ReNTSCH, I. (1968), Med. Welt 20, $1304-1306$. - 86. BrAUN, H. J. \& Aly, F. W. (1969), Deut. Med. Wochenschr. 94, 114-118. 87. Fishrin, B. G., Glassy, F. J., Hatrersiex, P. G., Hirose, F. M. \& Spiegelderg, H. L. (1970), Amer. J. Clin. Pathol. 53, 209-214. - 88. Pruzanskr, W. \& Rother, I. (1970), Can. Med. Ass. J. 102, 1061-1065. - 89. TeRRY, W. D., FAHEY, J. L. \& SteINBERG, A. G. (1965), J. Exp. Med. 122, 1087-1102. - 90. Kindler, U., Pietrek, G. \& HünIng, G. (1970), Deut. Med. Wochenschr. $95,2275-2280$.

Prof. Dr. A. Oberdorfer

Institut für Klin. Chemie u. Klin. Biochemie der Techn. Universität München

8 München 80

Ismaninger Str. 22

Deutschland 